DOI: $10.12731 / 2070-7568-2020-2-30-48$

УДК 338

\title{
ФАКТОРЫ ПОВЫШЕНИЯ ПРОИЗВОДИТЕЛЬНОСТИ ТРУДА РОССИЙСКИХ ПРОИЗВОДИТЕЛЕЙ АВТОКОМПОНЕНТОВ
}

\author{
Бербасова Л.В., Наумова О.А.
}

Данная работа посвящена анализу деятельности российских производителей на рынке автокомплектующих, в частности производительности труда как основной характеристике конкурентоспособности. В работе определены проблемы отечественных производителей автокомпонентов, выявлены основные причины отставания производительности труда российских компаний от зарубежных, а также предложены способы ее повышения посредством внедрения инструментов бережливого производства или дифференциачии продукта. Данными для расчета послужили материаль предприятий-участников национального проекта «Производительность труда».

Цель работы: определение факторов, обуславливающих сущчествование отставания производительности труда российских и зарубежных производителей автокомплектующих и путей ее повышения.

Метод или методология проведения работы: были использованы аналитический, системный и сравнительный подходы в части выявления ключевых проблем отрасли и их причин, а также совокупность методов экономико-статистического анализа при количественной оченке сформулированных выводов.

Результаты: сформулированы основные проблемы российских производителей автокомпонентов и предложены пути их решения.

Область применения результатов: полученнье результать целесообразно применять экономическим субъектам, осуществляющим производство автокомплектующих, при разработке стратегии повышения производительности труда. 
Ключевые слова: автокомпоненты; производительность труда; дифференцииччи продукта; оптимизащчия затрат; бережливое производство.

\section{FACTORS OF INCREASING LABOR PRODUCTIVITY OF RUSSIAN MANUFACTURERS OF AUTO COMPONENTS}

\section{Berbasova L.V., Naumova O.A.}

This work is devoted to the analysis of the activities of Russian manufacturers in the market of auto components, in particular labor productivity as the main characteristic of competitiveness. The work identifies the problems of domestic manufacturers of automotive components, identifies the main reasons for the lag in labor productivity of Russian companies from foreign ones, and also suggests ways to increase it through the introduction of lean manufacturing tools or product differentiation. The data for the calculation were the materials of enterprises participating in the national project "Labor Productivity".

Purpose: determination of factors causing the existence of lag in labor productivity of Russian and foreign manufacturers of auto parts and ways to increase it.

Method or methodology of the work: analytical, systemic and comparative approaches were used to identify key industry problems and their causes, as well as a set of methods of economic and statistical analysis for the quantitative assessment of the conclusions drawn.

Results: the main problems of Russian manufacturers of automotive components are formulated and ways to solve them are proposed.

Practical implications: the results can be applied to economic entities engaged in the production of auto components in the development of a strategy to increase labor productivity.

Keywords: auto components; labor productivity; product differentiation; cost optimization; lean production. 


\section{Введение}

На данный момент в Российской Федерации осуществляют деятельность порядка 1500 юридических лиц, основным видом экономической деятельности которых является производство комплектующих и принадлежностей для автотранспортных средств, их структура приведена на рисунке 1.

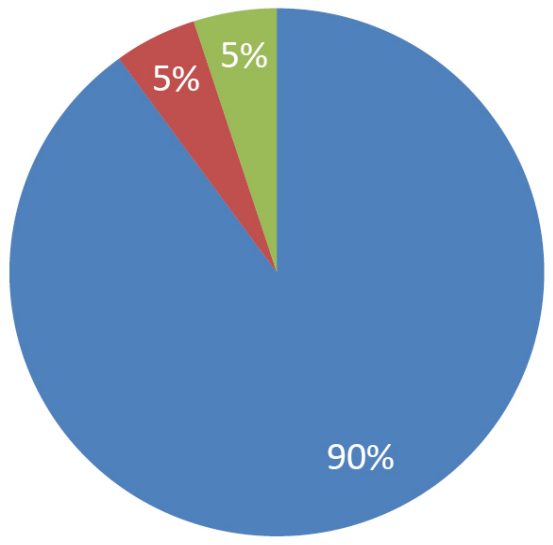

- Малые предприятия и микропредприятия

- Крупные предприятия

Средние предпритяия

Рис. 1. Структура производителей автокомпонентов в России, $\%$ от общего числа

Данные предприятия предоставляют рабочие места примерно для 80 тыс. человек. В 2018 году объем производства по ОКВЭД 29.3 составил более 400 млрд руб., что эквивалентно примерно 0,4\% ВВП России.

Ключевыми регионами, на территории которых располагается большая часть предприятий отрасли, являются Приволжский, Северо-Западный и Центральный федеральные округа. Данные регионы являются ключевыми центрами (кластерами) автомобильной промышленности России. Распределение выручки отрасли производства автокомпонентов по итогам 2018 года по субъектам РФ представлено на рисунке 2. На предприятиях отрасли, расположенных в вышеуказанных субъектах РФ, трудится около 60\% работников всех производителей автокомпонентов с выручкой более 100 млн рублей. 


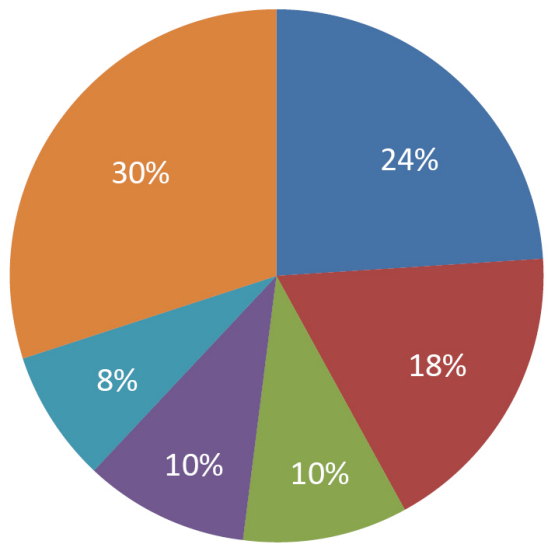

Санкт-Петербург и Ленинградская область

Самарская область

- Нижегородская область

Калужская область

Республика Татарстан

Рис. 2. Распределение выручки отрасли производства автокомпонентов по субъектам РФ, \% от общего числа

Основными потребителями продукции данных предприятий являются автопроизводители, сконцентрированные на территориях автомобильных кластеров, приведенных в таблице 1.

Таблииа 1.

Ключевые центры автомобильной промышленности России

\begin{tabular}{|c|c|c|c|}
\hline $\begin{array}{c}\text { № } \\
\text { п/п }\end{array}$ & $\begin{array}{c}\text { Федеральный } \\
\text { округ }\end{array}$ & $\begin{array}{c}\text { Доля в общем } \\
\text { выпуске }\end{array}$ & $\begin{array}{c}\text { Основные } \\
\text { производители }\end{array}$ \\
\hline 1 & Приволжский & $38 \%$ & АВТОВАЗ, КАМА3, Volkswagen \\
\hline 2 & Северо-Западный & $31 \%$ & Hyundai, Toyota, Nissan, Aвтотор \\
\hline 3 & Центральный & $14 \%$ & $\begin{array}{c}\text { Renault, Mercedes, Volkswagen, } \\
\text { ПСMА }\end{array}$ \\
\hline \multicolumn{2}{|c|}{} \\
\cline { 2 - 3 }
\end{tabular}

Источник: разработано автором.

Исследовательская база по проблематике производительности труда является весьма обширной. В работе Н.Н. Шиловой определяется эффективность автоматизации как основного инструмента повышения производительности труда, при этом не затронуты социальные вопросы этого направления [3]. Исследование Ю.В. Елисеевой посвящено изучению влияния инновационного развития на качество деятельности хозяйствующего субъекта в целом [4]. В работе А.В. Матвиенко про- 
анализирован опыт компаний, применяющих стратегию дифференциации продукции в целях повышения производительности труда в современных рыночных условиях [9]. Развитие отечественных предприятий посредством применения инструмента сетевого партнерства рассмотрено в исследовании С.В. Старикова [10]. В работе И.Д. Котлярова проанализирована сущность локализации производства как эффективного инструмента догоняющего развития, позволяющего формировать собственную цепочку создания стоимости внутри страны, а в исследовании Т.В. Кирилловой определены факторы, способствующие развитию автосборочных производств в России, расширению импортозамещения и росту экспортного потенциала страны в целом $[5,6]$. Каждая из отраслей имеет свои особенности функционирования, проблематику и причины отставания от развитых стран в сфере производительности труда. Вопросы производительности труда именно в сфере производства автокомплектующих до сих пор недостаточно изучены. Представляется необходимым дать комплексную оценку факторов повышения производительности труда, взаимодополняющих друг друга.

Цель работы заключается в определении факторов, обуславливающих существование отставания производительности труда российских и зарубежных производителей автокомплектующих и путей ее повышения.

\section{Материалы и методы исследования}

Информационной базой исследования являются национальные статистические системы и базы данных. В работе были использованы аналитический, системный и сравнительный подходы в части выявления ключевых проблем отрасли и их причин, а также совокупность методов экономико-статистического анализа при количественной оценке сформулированных выводов.

\section{Результаты исследования и их обсуждение}

В целях сравнения производительности труда российских и зарубежных производителей автокомпонентов была проведена оценка производительности труда 85 крупнейших российских производи- 
телей автокомпонентов с выручкой более 200 млн рублей и численностью сотрудников более 100 человек, а также ряда крупнейших международных компаний, входящих в топ-100 мировых производителей автокомпонентов, агрегированных по страновой принадлежности (рисунок 3). Методика расчета производительности труда: ДС $\div$ Чср, где ДС-это добавленная стоимость, созданная компанией за определенный период времени, Чср - среднесписочная численность сотрудников [8].

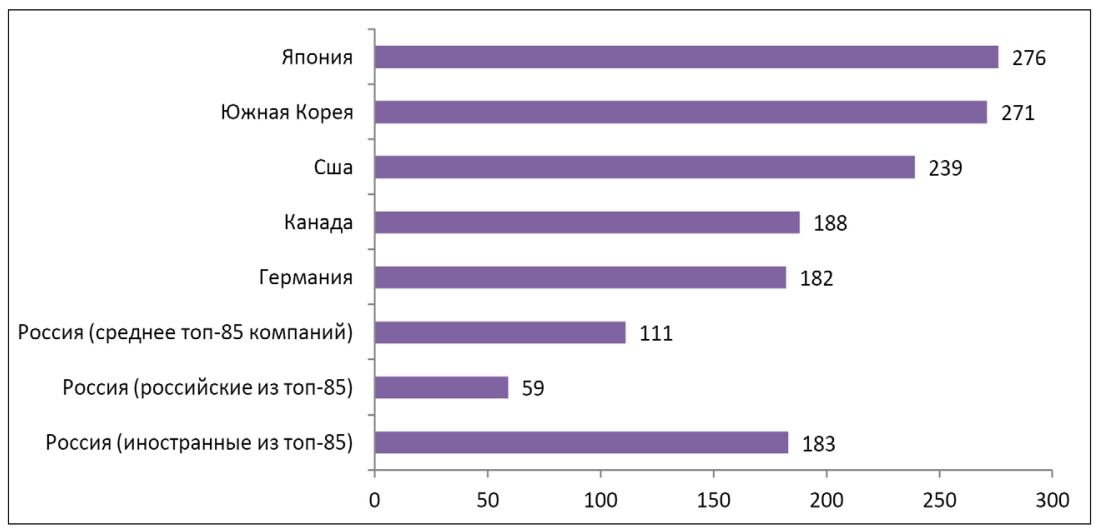

Рис. 3. Производительность труда в сфере производства автокомпонентов (тыс. долл. США/чел.)

В целом уровень производительности труда российских предприятий отстает от ведущих глобальных компаний примерно в 2 раза. Если проводить сравнение мирового уровня производительности труда с производительностью труда российских компаний, не имеющих зарубежных «корней», то отставание еще заметнее - почти в 4 раза от лучших мировых практик. Производительность труда иностранных компаний, осуществляющих деятельность на территории России, находится практически на таком же уровне, как и у ведущих компаний по производству автокомпонентов за рубежом.

Иностранные производители автокомпонентов в России являются лидерами по выручке. Среди производителей автокомпонентов России в 2018 году компании с иностранным участием составляют 
не более 10\%. При этом данные компании генерируют 54\% выручки отрасли.

Из 30 крупнейших производителей автокомпонентов в России только 8 являются российскими компаниями.

По нашему мнению, существенная разница в производительности российских и зарубежных компаний может объясняться различными факторами и особенностями:

- уровнем автоматизации: зарубежные компании чаще инвестируют в автоматизацию и роботизацию процессов, в связи с чем потребность в ручном труде у них значительно меньше;

- уровнем локализации производства: зарубежные компании, локализованные в России, закупают значительную долю компонентов за рубежом, и им не требуется держать в России сотрудников, занимающихся их производством, таким образом, они генерируют ту же выручку при меньшем количестве людей;

- качеством и инновационностью продукции: технологии международных компаний позволяют им создавать более качественный продукт и продавать его дороже. За счет этого фактора увеличивается числитель показателя производительности, что является ключевым направлением развития государственных программ по производительности с целью сохранения рабочих мест $[3,4,6,10]$.

При анализе уровня автоматизации и фондовооруженности производств было выявлено, что остаточная стоимость основных средств у зарубежных компаний в среднем составляет 1,9 млн рублей на 1 сотрудника, у российских - 0,4 [14]. Это говорит о больших инвестициях иностранных производителей в современное оборудование, требующее меньших затрат труда, и, соответственно, позволяющее держать в штате значительно меньше сотрудников. Численность штата российских компаний, производящих автокомпоненты, в среднем на 40\% выше, чем в зарубежных.

Именно поэтому даже с учетом более низкого уровня оплаты труда российские предприятия имеют почти в два раза большую долю ФОТ в затратах по сравнению с зарубежными (20\% и $11 \%$ 
соответственно). Высокая доля ФОТ объясняется использованием устаревшего оборудования, требующего больших трудозатрат, и низкой эффективностью работы сотрудников. Зарубежные предприятия имеют заметно большую долю материальных затрат по сравнению с российскими, что может говорить о более высоком качестве сырья, используемом ими в производстве или о разницах в продуктовом портфеле.

В качестве основных мер повышения конкурентоспособности нами предлагаются две общеизвестные стратегии: оптимизация затрат и дифференциация продукта. Анализ международных производителей автокомплектующих показывает, что обе стратегии позволяют обеспечивать конкурентоспособность и добиваться положительных финансовых результатов $[15,16,17]$.

В зависимости от положения в отрасли для российских производителей может быть актуальна как стратегия развития продукта и инноваций, так и стратегия оптимизации затрат за счет совершенствования процессов. Первая стратегия в наибольшей степени подойдет крупным диверсифицированным компаниям, вторая - небольшим специализированным производителям.

Для компаний, выбравших путь дифференциации и создания новых продуктов, принципиально важно своевременно обновлять продуктовый портфель, соучаствовать с автопроизводителями в разработке новых решений и стратегически подходить к выбору своего места в цепочке создания стоимости. Наиболее подробно данная стратегия описана в исследованиях А.В. Матвиенко [9].

Внедрение инноваций в производственный процесс, так же как и разработка нового продукта, требует значительных финансовых ресурсов, а также развитой внутренней НИОКР экспертизы. В случаях, если внедряемая инновация только частично обеспечивается компетенциями предприятия-инициатора, перспективным ресурсом для расширения экспертизы является партнерство с другими компаниями в отрасли либо с компаниями в смежных отраслях. Партнерство может быть построено по принципу горизонтальной интеграции (объединение компаний, находящихся на одном уров- 
не производственной цепочки) или вертикальной интеграции (например, партнерство между автопроизводителем и поставщиками различных уровней). В настоящее время применение вертикальной интеграции затруднено из-за ограниченности ресурсов российских компаний, что приводит к необходимости создания инновационных форм аккумулирования ресурсов предприятий без единоличного владения и контроля над ними. В качестве решения задачи организации эффективного сотрудничества отечественных производителей и исключения зависимости от иностранных поставщиков может быть предложено выстраивание многоуровневой сетевой кооперации, обеспечивающей формирование полноценной цепочки создания ценности внутри страны. В рамках сетевого сотрудничества осуществляется объединение ресурсов предприятий, у головной компании отсутствует необходимость в приобретении предшествующих переделов и сопутствующих производств, так как они вовлечены в организацию совместной деятельности, а высвободившиеся ресурсы могут быть использованы в качестве вложений в техническое перевооружение предшествующих переделов. Единство производственной системы при данном типе партнерства обеспечивается единой информационной системой сопровождения производства [10].

Примером сетевого сотрудничества в автомобильной промышленности является партнерство между отраслевыми предприятиями и высокотехнологичными компаниями (IT-разработчики, производители электроники). Ярким примером такого партнерства в России является сотрудничество между КАМАЗ, ІТ-компаниями «ВИСТ групп» и «Cognitive Technologies» в сфере разработки системы интеллектуального управления грузовыми автомобилями. К 2025-2027 году КАМАЗ планирует создание коммерческого образца беспилотного грузовика [12].

Развитие различных видов взаимодействий между субъектами хозяйствования, появление метафирм в различных отраслях, представляется еще одной возможностью для повышения производительности за счет, сокращения внутрипроизводственных затрат и 
повышению продаж. Одним из факторов тормозящим этот процесс является консервативный подход к управлению, особенно в «тяжелых» производственных отраслях [7].

Поскольку на проведение НИОКР зарубежными компаниями выделяются значительно большие средства, чем в России (в среднем $4 \%$ от выручки за рубежом по сравнению с более $1 \%$ в России), технологический уровень зарубежных компаний дает им конкурентное преимущество за счет качественных характеристик продуктов.

Следует отметить, что российские предприятия не являются глобальными и не достигают масштабов ведущих мировых производителей. Это ограничивает их возможности в части долгосрочных инвестиций и создания прорывных инноваций. Тем не менее, крупные диверсифицированные компании могут играть роль «инноваторов-последователей» и создавать продукты по аналогии с лидерами рынка. Устоявшиеся связи с локальными автопроизводителями, сравнительно низкая стоимость интеллектуального труда в России и протекционная государственная политика могут помочь в поддержании конкурентных позиций на рынке.

С учетом ограниченных ресурсов для локальных специализированных компаний приоритетом должны быть оптимизация процессов и последовательное сокращение затрат. Важными рычагами для этого является минимизация производственных потерь времени и материалов, а также автоматизация. При этом важно сохранять актуальность продуктового предложения для рынка и обновлять продукты хотя бы с темпом большинства других компаний, не оказываясь в хвосте морально устаревших «опоздавших». Компании, которые не смогут ни создать современные продукты, ни достигнуть лидерства в издержках, рискуют в сравнительно короткие сроки покинуть рынок.

Оптимизация производственных процессов посредством различных управленческих технологий обеспечивает ряд конкурентных преимуществ, они приведены на рисунке 4. Основными инструментами оптимизации затрат выступают научный подход к организации труда и внедрение инструментов автоматизации производства. Ис- 
пользование данных инструментов способствует повышению качества продукции и снижению человеческого фактора в производстве. Снижение доли бракованной продукции, в свою очередь, вызывает снижение затрат на материалы. Также повышение эффективности производственных процессов способствует кадровой оптимизации: при использовании автоматизированных линий на производственную операцию требуется меньшее количество времени сотрудников, а некоторые операции становятся «безлюдными».

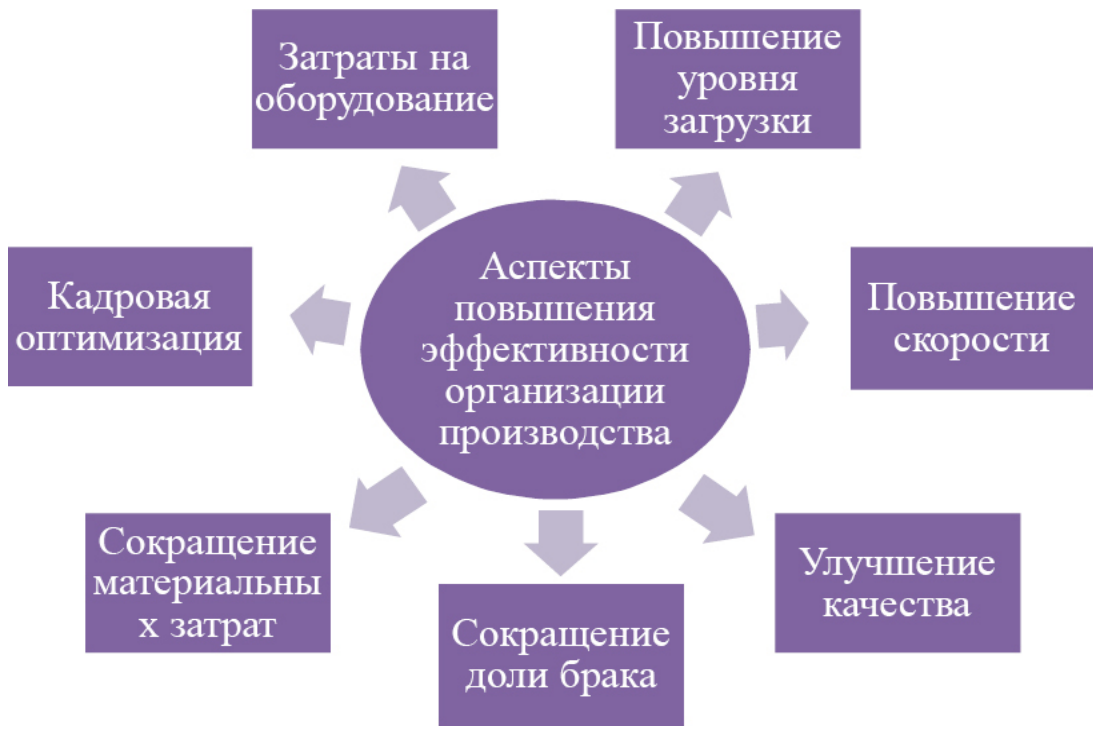

Рис. 4. Конкурентные преимущества при осуществлении стратегии оптимизации затрат

В мае 2018 года Указом Президента РФ № 204 «О национальных целях и стратегических задачах развития Российской Федерации на период до 2024 года» перед Правительством РФ совместно с органами государственной власти субъектов Российской Федерации к 2024 году были поставлены следующие задачи:

- стимулирование внедрения передовых управленческих, организационных и технологических решений для повышения производительности труда и модернизации основных фондов, 
в том числе посредством предоставления налоговых преференций;

- сокращение нормативно-правовых и административных ограничений, препятствующих росту производительности труда, а также замещение устаревших и непроизводительных рабочих мест;

- формирование системы методической и организационной поддержки повышения производительности труда на предприятиях;

- формирование системы подготовки кадров, направленной на обучение основам повышения производительности труда, в том числе посредством использования цифровых технологий и платформенных решений [1].

В декабре 2018 года во исполнение данного Указа Министерством экономического развития РФ был разработан паспорт национального проекта «Производительность труда и поддержка занятости».

Национальным проектом «Повышение производительности труда и поддержка занятости» предусмотрена финансовая поддержка предприятий в реализации проектов, направленных на повышение производительности труда: до 300 млн руб. на период до 5 лет под $1 \%$ годовых, при соблюдении ряда условий. Обязательным условием получения займа по данной программе является получение заключения (сертификата) ФЦК о наличии ключевых элементов производственной системы и достаточного уровня использования внутренних ресурсов повышения производительности [2].

В таблице 2 представлены участники национального проекта, занимающиеся производством автокомплектующих, и их результаты по увеличению эффективности организации производственного процесса. На основе этих данных можно сделать вывод о положительном влиянии функционирования национального проекта на уровень производительности труда предприятий. 
Таблиияа 2.

Результаты участия предприятий в национальном проекте

\begin{tabular}{|c|c|c|}
\hline Компания & $\begin{array}{c}\text { Инструменты повышения } \\
\text { эффективности производ- } \\
\text { ства } \\
\end{array}$ & Результаты \\
\hline $\begin{array}{l}\text { ООО «САA3 } \\
\text { Комплект» }\end{array}$ & $\begin{array}{l}\text { Исключение перемещений } \\
\text { работников в процессе изго- } \\
\text { товления изделий в } 3 \text { раза }\end{array}$ & $\begin{array}{l}\text { Выработка увеличилась на } \\
11 \% \text { с 1,95 до 2,16 млн руб./чел }\end{array}$ \\
\hline $\begin{array}{l}\text { ООО «Самара- } \\
\text { автожгут» }\end{array}$ & $\begin{array}{l}\text { Внедрение системы непре- } \\
\text { рывных улучшений, устанав- } \\
\text { ливающей вознаграждения } \\
\text { работникам за предложение } \\
\text { инициатив по повышению } \\
\text { эффективности производства }\end{array}$ & $\begin{array}{l}\text { Производительность труда уве- } \\
\text { личилась на } 8 \% \text { с 1,55 до 1,67 } \\
\text { млн руб./чел }\end{array}$ \\
\hline $\begin{array}{l}\text { АО «MOTOP- } \\
\text { СУПЕР» }\end{array}$ & $\begin{array}{l}\text { Внедрение подхода «точно } \\
\text { в срок»- после получения } \\
\text { заказа от автопроизводите- } \\
\text { ля за } 4 \text { часа осуществляется } \\
\text { покраска заготовки бампера } \\
\text { в необходимый цвет и его } \\
\text { доставка до линии сборки }\end{array}$ & $\begin{array}{l}\text { Время протекания процесса } \\
\text { сократилось на } 94 \% \text {, выработ- } \\
\text { ка увеличилась на } 10 \% \text {, с } 3,61 \\
\text { до } 3,95 \text { млн руб./чел }\end{array}$ \\
\hline $\begin{array}{l}\text { ООО «Металло- } \\
\text { продукция» }\end{array}$ & $\begin{array}{l}\text { Осуществление вложений в } \\
\text { переоснащение оборудова- } \\
\text { ния для штамповки металла }\end{array}$ & $\begin{array}{l}\text { Временные потери при перена- } \\
\text { стройке оборудования сократи- } \\
\text { лись с } 5,5 \text { до } 2 \text { часов, производи- } \\
\text { тельность труда увеличилась на } \\
10 \text { \% с 2,28 до 2, } 51 \text { млн руб./чел }\end{array}$ \\
\hline $\begin{array}{l}\text { ЗАО «Производ- } \\
\text { ственная компа- } \\
\text { ния Автокомпо- } \\
\text { нент Тольятти» }\end{array}$ & $\begin{array}{l}\text { Частичная замена материала } \\
\text { автокомпонентов экстерье- } \\
\text { ра на пластик, оптимизация } \\
\text { расходов на упаковку }\end{array}$ & $\begin{array}{l}\text { Затраты на производство дан- } \\
\text { ных деталей снизились на } 8 \% \text {. } \\
\text { Выработка увеличилась на } 20 \% \\
\text { с } 3,11 \text { до } 3,74 \text { млн руб./чел }\end{array}$ \\
\hline
\end{tabular}

Источник: разработано автором.

\section{Заключение}

Использование производителями автокомпонентов современных разработок и технологий в части автоматизации и роботизации позволяет решить ряд технологических, производственных и экономических задач, в том числе:

- повысить качество выпускаемой продукции за счет унификации производственных процессов;

- расширить текущий уровень производства, снизить себесто- 
имость продукции за счет сокращения материальных и трудовых затрат при изготовлении различных комплектующих;

- повысить конкурентоспособность продукции за счет повышения ее качества.

По результатам анализа эффективности мер принятых участниками национального проекта «Производительность труда», занимающиеся производством автокомплектующих очевидно, что массового и универсального решения этой проблемы нет. Каждый из объектов исследования использовал свои инструменты, адекватные текущим условиям.

Авторами проведен обзор основных практик, учитывающих особенности отрасли и объединяющих результаты российских и иностранных компаний. В качестве основных мер повышения конкурентоспособности были предложены две общеизвестные стратегии: оптимизация затрат и дифференциация продукта. Определены их особенности реализации для предприятий производителей автокомплектующих.

В качестве основных рекомендаций можно обозначить внедрение инструментов этих стратегий в деятельность не директивно, не с целью самого внедрения, а поэтапно, с учетом конкретных условий производства и производственных участков. Только в этом случае, активное на сегодняшний день государственное участие позволит получить положительный эффект. Льготное государственное кредитование позволит использовать более дешевые ресурсы для достижения стратегических целей.

Таким образом, государственная поддержка производителей автокомплектующих, выделение компаниями большей доли средств на проведение НИОКР, а также повсеместное внедрение системы бережливого производства способны увеличить производительность труда на предприятиях и повысить их конкурентоспособность на мировом рынке.

\section{Сиисок литературы}

1. Указ Президента РФ от 07.05.2018 № 204 (ред. от 19.07.2018 г.) «О 
национальных целях и стратегических задачах развития Российской Федерации на период до 2024 года».

2. Паспорт национального проекта (программы) «Производительность труда и поддержка занятости»: [Электронный ресурс]: [сайт] http:// static.government.ru/media/files/Ki3g5TzKdmVyX2ogBvNTIxH3BQ6 YFADA.pdf (дата обращения 22.04.2020).

3. Ботнарь О.В., Наумчик К.А., Шилова Н.Н. Автоматизация бизнеспроцессов как фактор повышения производительности труда // Научное сообщество студентов XXI столетия. Экономические науки, 2017. № 4 (52). С. 20-26.

4. Елисеева Ю.В., Агафонова О.В. Влияние инноваций на эффективность деятельности организаций // Актуальные проблемы агропромышленного комплекса: сборник трудов научно-практической конференции преподавателей, студентов, магистрантов и аспирантов, посвященный к 80-летию Новосибирского ГАУ, 2016. С. 93-96.

5. Кириллова Т.В. Перспективы развития автосборочных производств и их вклад в развитие экспортного потенциала Российской Федерации // В мире научных открытий, 2015. № 5. С. 143-159.

6. Котляров И.Д. Локализация производства как инструмент импортозамещения // ЭКО, 2016. № 8. С. 128-140.

7. Котляров И.Д. Метафирма как форма организации хозяйственной деятельности // Управление экономикой: методы, модели, технологии. Материалы XV Международной научной конференции. T. 1. Уфимский государственный авиационный технический университет: Уфа, 2015. С. 88-91.

8. Криволапова К.О. Анализ производительности труда и оценка влияния отдельных факторов на производительность труда // Финансово-экономические и технологические проблемы развития регионов: сборник научных трудов по материалам Международной научнопрактической конференции молодых ученых, 2019. С. 120-122.

9. Матвиенко А.В. Стратегическое поведение фирм в условиях дифференциации продукта // Актуальные проблемы экономики и управления: теоретические и прикладные аспекты: материалы Третьей международной научно-практической конференции, 2018. С. 284-290. 
10. Стариков С.В. Потенциал применения многоуровневого сетевого партнёрства в российской промышленности как инструмента развития импортозамещающих производств // Управленческое консультирование, 2017. № 8. С. 169-175.

11. Тарасова Т.В., Сенницкий А.А. Автоматизация производства как фактор повышения производительности труда // Colloquium-journal, 2019. № 7-7 (31). С. 74-75.

12. Сайт Интерфакс: [Электронный ресурс]: [сайт] https://www.interfax. ru/russia/705574 (дата обращения 22.04.2020).

13. Сайт Росстата: [Электронный ресурс]: [сайт] http://www.gks.ru (дата обращения 22.04.2020).

14.Исследование ФЦК передовой российской и зарубежной практики повышения производительности труда в сфере производства комплектующих и принадлежностей для автотранспортных средств: [Электронный ресурс]: [сайт] https:/производительность.pф/ documents/153.pdf (дата обращения 22.04.2020).

15. Bjuggren C. M. Employment protection and labor productivity // Journal of Public Economics, 2018, pp. 138-157.

16. Janssen M.C.W., Teteryatnikova M. Horizontal product differentiation: disclosure and competition // The Journal of Industrial Economics, 2016. V. 64. № 4, pp. 589-620.

17. Üngör M. Productivity growth and labor reallocation: Latin America versus East Asia // Review of economic dynamics, 2017, pp. 25-42.

\section{References}

1. Decree of the President of the Russian Federation of 07.05.2018 No. 204 (ed. of 19.07.2018) «On national goals and strategic objectives of the development of the Russian Federation for the period up to 2024».

2. Passport of the national project (program) "Labor Productivity and Employment Support”. http://static.government.ru/media/files/Ki3g5TzKdmVyX2ogBvNTIxH3BQ6YFADA.pdf (date accessed 04.22.2020).

3. Botnar' O.V., Naumchik K.A., Shilova N.N. Avtomatizatsiya biznes-protsessov kak faktor povysheniya proizvoditel'nosti truda [Automation of business processes as a factor in increasing labor productivity]. Nauchnoe 
soobshchestvo studentov XXI stoletiya. Ekonomicheskie nauki, 2017. № 4 (52), pp. 20-26.

4. Eliseeva Yu.V., Agafonova O.V. Vliyanie innovatsiy na effektivnost' deyatel'nosti organizatsiy [The impact of innovation on organizational performance]. Aktual'nye problemy agropromyshlennogo kompleksa: sbornik trudov nauchno-prakticheskoy konferentsii prepodavateley, studentov, magistrantov $i$ aspirantov, posvyashchennyy $k$ 80-letiyu Novosibirskogo GAU [Actual problems of the agro-industrial complex: collection of works of the scientific and practical conference of teachers, students, undergraduates and graduate students, dedicated to the 80th anniversary of Novosibirsk State Agrarian University], 2016, pp. 93-96.

5. Kirillova T.V. Perspektivy razvitiya avtosborochnykh proizvodstv i ikh vklad v razvitie eksportnogo potentsiala Rossiyskoy Federatsii [Prospects for the development of car assembly plants and their contribution to the development of the export potential of the Russian Federation]. $V$ mire nauchnykh otkrytiy, 2015. № 5, pp. 143-159.

6. Kotlyarov I.D. Lokalizatsiya proizvodstva kak instrument importozameshche-niya [Localization of production as an instrument of import substitution]. EKO, 2016. № 8, pp. 128-140.

7. Kotlyarov I.D. Metafirma kak forma organizatsii khozyaystvennoy deyatel'nosti [Metafirm as a form of business organization]. Upravlenie ekonomikoy: metody, modeli, tekhnologii. Materialy XV Mezhdunarodnoy nauchnoy konferentsii. T. 1 [Management of the economy: methods, models, technologies. Materials of the XV International Scientific Conference. V. 1]. Ufa State Aviation Technical University: Ufa, 2015, pp. 88-91.

8. Krivolapova, K.O. Analiz proizvoditel'nosti truda i otsenka vliyaniya otdel'nykh faktorov na proizvoditel'nost' truda [Analysis of labor productivity and assessment of the influence of individual factors on labor productivity]. Finansovo-ekonomicheskie i tekhnologicheskie problemy razvitiya regionov: sbornik nauchnykh trudov po materialam Mezhdunarodnoy nauchno-prakticheskoy konferentsii molodykh uchenykh [Financial, economic and technological problems of regional development: a collection of scientific papers based on the materials of the International Scientific and Practical Conference of Young Scientists], 2019, pp. 120-122. 
9. Matvienko A.V. Strategicheskoe povedenie firm v usloviyakh differentsiatsii produkta [Strategic behavior of firms in the context of product differentiation]. Aktual'nye problemy ekonomiki i upravleniya: teoreticheskie i prikladnye aspekty: materialy Tret'ey mezhdunarodnoy nauchno-prakticheskoy konferentsii [Actual problems of economics and management: theoretical and applied aspects: materials of the Third International Scientific and Practical Conference], 2018, pp. 284-290.

10. Starikov S.V. Potentsial primeneniya mnogourovnevogo setevogo partner-stva $\mathrm{v}$ rossiyskoy promyshlennosti kak instrumenta razvitiya importoza-meshchayushchikh proizvodstv [The potential use of multilevel network partnerships in Russian industry as a tool for the development of import-substituting industries]. Upravlencheskoe konsul'tirovanie, 2017. № 8, pp. 169-175.

11. Tarasova T.V., Sennitskiy A.A. Avtomatizatsiya proizvodstva kak faktor povysheniya proizvoditel'nosti truda [Automation of production as a factor in increasing labor productivity]. Colloquium-journal, 2019. № 7-7 (31), pp. 74-75.

12.https://www.interfax.ru/russia/705574 (date accessed 22.04.2020).

13.http://www.gks.ru (date accessed 22.04.2020).

14. Issledovanie FTSK peredovoy rossiyskoy $i$ zarubezhnoy praktiki povysheniya proizvoditel'nosti truda $v$ sfere proizvodstva komplektuyushchikh $i$ prinadlezhnostey dlya avtotransportnykh sredstv [The FCC study of the best Russian and foreign practices of increasing labor productivity in the production of components and accessories for motor vehicles]. https:// производительность.pф/documents/153.pdf(date accessed 22.04.2020).

15. Bjuggren C.M. Employment protection and labor productivity. Journal of Public Economics, 2018, pp. 138-157.

16. Janssen M.C.W., Teteryatnikova M. Horizontal product differentiation: disclosure and competition. The Journal of Industrial Economics, 2016. V. 64. № 4, pp. 589-620.

17. Üngör M. Productivity growth and labor reallocation: Latin America versus East Asia. Review of economic dynamics, 2017, pp. 25-42. 


\section{ДАННЫЕ ОБ АВТОРАХ}

Бербасова Лада Владимировна, студент направления «Бухгалтерский учет, анализ и аудит»

Самарский государственный экономический университет ул. Советской Армии, 141, г. Самара, 443090, Российская Федерация

lada-berbasovaa@mail.ru

Наумова Ольга Александровна, доцент кафедры учета, анализа и экономической безопасности, кандидат экономических наук Самарский государственный экономический университет ул. Советской Армии, 141, г. Самара, 443090, Российская Федеращия naumovaoa@gmail.com

\section{DATA ABOUT THE AUTHORS}

Berbasova Lada Vladimirovna, student of the direction "Accounting, Analysis and Audit"

Samara State University of Economics

141, Soviet Army Str., Samara, 443090, Russian Federation lada-berbasovaa@mail.ru

SPIN-code: 7253-1767

Naumova Olga Aleksandrovna, Associate Professor of the Department of Accounting, Analysis and Economic security, Candidate of Economic Sciences

Samara State University of Economics

141, Soviet Army Str., Samara, 443090, Russian Federation

naumovaoa@gmail.com

SPIN-code: 6958-6771

ResearcherID: X-7035-2019

Scopus Author ID: 57191284964 